\title{
Twin Gastrulæ and Bipinnariæ of Luidia sarsi, Düben, and Koren.
}

\author{
By
}

James F. Gemmill, M.A., M.D., D.Sc.

With Figures Pls. I-III (Figs. 1-21).

EARLY in June of this year (1914) I received from the Plymouth Marine Laboratory through the kindness of Dr. E. J. Allen, F.R.S., several Thermos flasks containing quantities of a culture of Luidia in the early blastula stage. This culture was made for me by Mr. James Gray, King's College, Cambridge, to whom, and to Dr. Allen, I desire herewith to express my indebtedness. The larvæ were little the worse of the journey to Glasgow, but it seemed to me that they showed even greater irregularities of form than might have been expected from Mortensen's (13) description of blastula formation in our species. However, in the end, abundance of perfectly typical young bipinnariæ* were secured from the contents of the various flasks. The abnormal larvæ became gradually fewer through death, and those which survived could be isolated without much trouble, since they exhibited less capacity for keeping near the surface of the water than their healthier brethren. A great many of the early malformations were of the nature of double or twin formation, and it soon became evident that the teratological type in question, namely, double monstrosity, was about to receive a more varied expression, and to attain a more advanced stage in development, than it had ever before been my good fortune to find in any starfish culture.

In the accompanying illustrations two series of abnormal larvæ are figured, one at the gastrula stage (Figs. 1-11), and the other at that of the early bipinnaria (13-21). As a description is appended to each figure, only questions of general interest need be dealt with here.

Classification. In the systematic teratology of vertebrates, Double

* Two points in normal derelopment may be noted here. (1) There does not appear to be an auricularia stage in the formation of the bipinnaria, the preoral and postoral bands being separated from one another antero-dorsally by a distinct interval at the time when they are first recognisably differentiated in this field (see 7, p. 232). Indeed, the relatively great width of the interval in question would by itself enable us to distinguish the larva of Luidia from those of Asterias rubens, A. glacialis, and Porania pulvillus during the first fortnight of bipinnarial life. (2) The small structure arising posteriorly from endoderm and interpreted by me as a rudimentary posterior enterocoelic growth in Asterias rubens, A. glacialis, and Porania pulvillus does not appear to be formed in Luidia (see 7, p. 233). 
Monstrosities are conveniently divided up into Anadidymi, Katadidymi, Anakatadidymi, Mesodidymi $(5 ; 14 ; 6$, p. 3$)$. To these a small group falls to be added containing the few recorded examples of simple longitudinal or parallel union $(6, \mathrm{pp} .4,29)$, which I venture to suggest may suitably be termed Paradidymi. The Anadidymi are, of course, forms with the anterior end more or less double, and the posterior end single; in the Katadidymi these conditions are reversed. The Anakatadidymi show anterior and posterior doubling, but are single in their middle regions, while the converse relations are characteristic of the Mesodidymi. In the Paradidymi doubling occurs in an equal or sub-equal degree throughout the whole of the longitudinal axis of the twins.

In fishes and other vertebrates, the notochord, the vertebral column, the central nervous system and the alimentary canal, serve as our principal guides in judging to which group a particular double monster should be assigned. In double bipinnariæ, on the other hand, we have to depend entirely on the alimentary canal, inasmuch as the only other easily recognisable longitudinal structure, namely, the posterior ciliated band, owing to its superficial position, in most cases shows a greatly lessened amount of doubling through the working of "regulation" processes. Nevertheless, if the alimentary canal be taken as a guide, it is remarkable how readily the various types of duplex bipinnariæ fall into the same kinds of groups as double-monster fishes. Thus Figs. 13 and 14 illustrate longitudinal or parallel union and are therefore Paradidymi; Figs. 16 and 17 belong to the Anadidymi ; Figs. 18 and 19 to the Katadidymi ; Fig. 20 is Anakatadidymous, and Fig. 21 Mesodidymous in type. Probably, further search among the abnormal bipinnariæ would have revealed a still fuller and more representative series. There remains to make mention of Fig. 15, which illustrates what may be called tangential union, and would no doubt have included the bipinnaria from the larva shown in Fig. 7 had survival been allowed. The twin embryonic axes, as represented here by the alimentary canals, are independent of, and widely divergent from, one another, but there is superficial union of the lateral or frontal body-walls. Among monster fishes we have no exact counterpart of this type, since, owing to the manner in which the twin embryonic axes develop, practically the only alternative to axial union is an Anakatadidymus effected through the intermediary of the yolk-sac. However, in the amniotic vertebrates, and particularly in the mammals, numerous instances occur in which, without axial union being present, the twin organisms are united to one another by paraxial or superficial structures. 
The twin bipinnariæ of Luidia are not directly comparable with the double Echinus-rudiments noted by Metschnikoff (11) and described in detail by MacBride (10), since the latter appear late in development, and their formation is a consequence of the abnormal persistence and differentiation of one particular organ, viz. a right hydrocoele. The same thing is true of the changes characteristic of double hydrocoele in the developing Asterias larva (7, p. 275). As regards structure, suggestive analogies can be drawn between our bipinnariæ and the abnormal medusæ described by Allmann (1) and Browne (2). In normal embryology perhaps the most interesting parallel is to be found in the development of the Annelid Lumbricus trapezoides Dugès, in which a double gastrula, giving rise to two complete earthworms, is produced by fission of the segmenting cell-mass (9). The converse process, namely, fusion of two ova, has been shown to be possible before (16 Ascaris) and after (16 Ascaris, 3 Spharechinus) fertilisation, and also during the blastula stage (12 Sphorechinus). In general, such fusion tends to produce double monstrosities resembling our bipinnariæ, but sometimes a perfectly single organism of larger than normal size is the result $(16 ; 3)$.

Causation. E. Haeckel $(8,1869)$ discovered that the segmented egg of a Siphonophore (Crystallodes), if artificially divided, could give rise to several partial embryos, and E. B. Wilson $(15,1893)$ found that during the early stages of segmentation in Amphioxus each of the component cells, if separated from the rest, could develop into a perfect gastrula, while imperfectly double gastrulæ occurred abundantly in cultures which had been subjected to shaking during the two-celled stage. A series of such gastrulæ is shown in 15, Pl. XXXIV, Figs. 66-73, while in Pl. XXXVII, some of the partially double stages which led up to them (four-celled, eight-celled, blastulæ) are also illustrated. As is well known, similar or allied phenomena have been demonstrated to occur in the development of many other ova, and there is now an extensive body of literature dealing with experiments on the subject. Without going into details for other groups, we may note that the ova of Asteroids were early found to react to experiment in much the same way as those of Amphioxus, and, what is more remarkable, it was ascertained by Driesch (3) that as late as the blastula stage either half of a developing ovum (Asterias glacialis, Astropecten) bisected transversely or longitudinally could give rise to a bipinnaria. Thus in Asteroids it appears that single cells in the earliest stages or cell masses at a later stage can, if isolated, produce whole larvæ. On the other hand, if the cells or cell masses in 
question are incompletely separated from one another, partial doubling or twin formation may result.

Usually in starfish ova, doubling of this kind is associated with disturbances so profound that differentiation ceases in the gastrula stage. In my own experience great numbers of partially double blastulæ have appeared in different cultures of Asterias rubens, A. glacialis, and Porania pulvillus, but none of these was observed to reach even the early bipinnarial stages, and so far as I know such stages have not been figured or described. Possibly the ova of Luidia possess unusually great potentialities of duplex development, but we may, perhaps, conjecture that the long-continued shaking which the cultures would suffer during their journey (the Thermos flasks were left only three-quarters full for reasons connected with aeration) effected a physiological separation of masses of cells during the formation of the blastula, and at the same time diminished their vitality less than do the more abrupt experimental methods commonly employed in laboratory work.

Mode of Formation. Among Fishes the first noticeable feature in the genesis of double monstrosities is that two centres of gastrulation arise on the margin of the blastoderm. Next, the resulting embryonic axes are either brought together so as to unite posteriorly, producing the anadidymous type, or else remaining separate they give rise to anakatadidymous union of the embryos by means of the yolk-sac. The katadidymous condition is extremely rare, and, indeed, probably never occurs in perfect form. In the birds and mammals the larger proportion of double monsters arises in connection with two centres of embryo formation, but Katadidymus is not uncommon, being caused in most cases by fission of the posterior end of a developing embryonic axis. In fishes, birds, and mammals, since growth of the axis takes place almost entirely from before backwards, true anterior fission either does not occur or is extremely limited in extent. On the whole, we see that throughout the vertebrates the important feature in the production of double monstrosities is the presence of two foci of embryo formation, and that in the simplest group, the fishes, these foci are, to begin with, centres of gastrulation. As regards the Asteroids, a glance at the series of illustrations to this paper will show that here also the formation of two centres of gastrulation precedes bipinnarial twinning. Two more or less separate archentera are produced, and various other structures are partially or completely doubled. In the end the two archentera may remain separate from one another (Figs. 1-4, gastrulæ; Figs. 13-15, bipinnariæ), but if the foci of gastrulation are 
very close together, the infolding process may amalgamate them, giving rise to an archenteron bifid in front and single behind (Fig. 5, gastrula; Fig. 16, bipinnaria). Again, in the case of a markedly bi-lobed blastula an originally single invagination may, during inward growth, divide into two branches (Fig. 6, gastrula ; Fig. 17, bipinnaria), but we must often leave the question open whether there has been anterior fission or posterior fusion of archentera (Figs. 7, 8, gastrulæ). It is evident, further, that anterior fusion of the archentera can take place (Figs 9-11, gastrulæ; Fig. 19, bipinnaria). In Fig. 20 fusion of the expanded stomachal regions of the archentera is exhibited by a specimen with "back-to-back" union. Fig. 18, on the other hand, illustrates a case of "face-to-face" union in which the derivatives of two entirely separate archentera share a common buccal cavity. In Fig. 21 (Mesodidymus) the buccal cavity and rectum are single, while the œsophagus and stomach are doubled and there is a composite enterocoelic cavity between them. Fig. 7 shows triplicity in a modified form-the only instance of triplicity observed.

An examination of the various abnormal bipinnariæ figured will show that each archenteron tends to produce a pair of enterocoeles. In most cases all four persist (Figs. 13-15, 17, 18, 20). Sometimes two from different pairs (right of left pair and left of right pair) are united together (Figs. 19, 21). More rarely these two have either never been formed or have disappeared at a very early stage (Fig. 16).

As regards the ciliated bands we note that their preoral and postoral portions never become mixed-that is to say, the preoral portion of one "twin" always unites with the preoral of the other, and the postoral with the postoral. The general arrangement of these bands, and of the larval fields they enclose, makes it patent that quite remarkable powers of developmental " regulation" or " making the best of things" must in many cases have been at work.

\section{SUMMARY.}

The various types of twin Luidia larvæ may be classified according to the same system as Double Monstrosities among vertebrates, the alimentary canal of the larvæ being taken as their representative axial structure.

The causation depends on early partial separation of cells or of cell masses, accompanied by a minimal interference with the vitality of the whole. 
Doubling (partial or complete) of the gastrula invagination is the great step on which the differentiation of twin bipinnariæ depends.

This differentiation shows very markedly the working of " regulation" processes in the course of which, when union of structures occurs, the union is always between structures of homologous origin. Thus preoral and postoral bands, enterocoeles, and particular regions of the alimentary canal, unite each with its own counterpart.

\section{REFERENCES.}

1. Allmann, G. W. A Monograph of the Gymnoblastic or Tubularian Hydroids. Part II, pp. 202-3, Fig. 76.

2. Browne, E. T. A Report on Medusæ found in the Firth of Clyde. Proc. Roy. Soc. Edinb., Vol. 25, Pt. IX, p. 753.

3. Driesch, H. Studien über Regulationsvermögen. IV. Die Verschmelzung der Individualität bei Echinidenkeimen. Arch. f. Entw. M., Vol. 10, pp. 411-34.

4. Do., do., Altes u. Neues zur Entwickelungsphysiologie des jungen Asteridenkeimes. Arch. f. Entw. Mech., Vol. 20, pp. 1-20.

5. Förster. Missbildungen des Menschen, Jena, 1861, pp. 22, $29,34$.

6. Gemmill, J. F. The Teratology of Fishes, Glasgow, 1912.

7. Do., do., The Development and Certain Points in the Adult Structure of the Starfish Asterias rubens. Phil. Trans. Roy. Soc. London, 1914, B., pp. 213-94.

8. Haeckel, E. Zur Entwickelungsgeschichte der Siphonophoren. Utrecht, 1869, pp. 73-9.

9. Kleinenberg, N. The Development of the Earthworm Lumbricus trapezoides, Dugès. Quart. Journ. Micr. Sci., Vol. 19, 1879, pp. 206-44.

10. MacBride, E. W. Two Abnormal Plutei of Echinus. London, Q.J.M.S., Vol. 57, pp. 235-50.

11. Metschnikoff, E. Embryologische Mittheilungen über Echinodermen. III. Zur Kenntniss der Wassergefässanlage bei Asteriden u. Echinoiden. Zool. Anz., Vol. 7, 1884, pp. 62-5.

12. Morgan, T. H. The Formation of one Embryo from two Blastulæ. Arch. f. Entw. M., Vol. 2, pp. 65-71.

13. Mortensen, Th. On the Development of some British Echinoderms. Journ. Mar. Biol. Ass. U.K., Vol. 10, No. 1, pp. 1-18, 1913. 
14. Ellacher, J. Terata mesodidyma von Salmo salvelinus. Wiener Sitzber. Ak. Wiss. Naturw., Vol. 68, 1873, pp. 299-324.

15. Wilson, E. B. Amphioxus and the Mosaic Theory of Development. Journal of Morphology, Vol. 8, 1893, pp. 579-615.

16. Zur Strassen, O. Ueber die Riesenbildung bei Ascariseiern. Arch. f. Entw. M., Vol. 7, 1898, pp. 642-76. 


\title{
DESCRIPTION OF FIGURES.
}

\section{LETTERING EMPLOYED.}

\author{
b.cav. Buccal cavity. \\ bl. Blastopore (anus of larva). \\ ente. Enterocoele. \\ entc'. Region of archenteron which produces the enterocoele. \\ entc.l. Left enterocoele. \\ entc.r. Right enterocoele. \\ m.o. Mouth opening. \\ oes. Esophagus. \\ oes'. Region of archenteron which produces the œsophagus. \\ po.cil.bd. Postoral ciliated band. \\ pr.cil.bd. Preoral ciliated band. \\ rect. Rectum. \\ stom. Stomach. \\ stom'. Region of archenteron which gives rise to the stomach.
}

\section{PLATE I.}

FIGS. 1-4.-Examples in which the archentera from two foci of gastrulation have remained separate. In Fig. 1 the blastopores are near one another and the archentera are parallel and equally developed. Compare the bipinnarial stage shown in Fig. 13. In Fig. 2 the blastopores are again near one another, the archentera being unequal; compare the bipinnarial stage shown in Fig. 14, though in the latter the inequality has manifested itself later and been less pronounced. In Fig. 3 the blastopores are a considerable distance away from one another and the archentera are markedly unequal ; compare also Fig. 7. In Fig. 4 the foci of gastrulation have appeared on opposite sides of the larva.

Figs. 5-8.-Examples in which the blastopore being single, the archentera are bifid anteriorly. In Fig. 5 the doubling only affects the anterior or enterocoelic-asophageal part of the archenteron; cf. the bipinnariæ shown in Figs. 16 and 17. In Fig. 6 the doubling reaches as far back as the commencement of the stomach ; ef. anterior portion of the bipinnaria shown in Fig. 20. In Fig. 7 there is doubling to a like degree and in addition there is a small, entirely independent archenteron with its own blastoporic opening on one side; the larva thus exhibits a modified form of triplicity and is the only triple monster obtained. For parallel instances in Fishes see 6, pp. 33, 35. In Fig. 8 the doubling extends as far back as the stomachal region; cf. posterior half of the bipinnaria shown in Fig. 20.

Frgs. 9-11.-Examples in which there are two separate blastopores, but the archentera are united in front to a greater or less degree. In Fig. 9 the archentera are equal and fused only at their extreme anterior ends; cf. the bipinnaria shown in Fig. 19. In Fig. 10 there is the same condition, but the archentera are unequal. In Fig. 11 the union reaches back to the stomachal region. 
GEMMILL. TWIN GASTRUL

PLATE I.

AND BIPINNARIÆ OF LUIDIA.

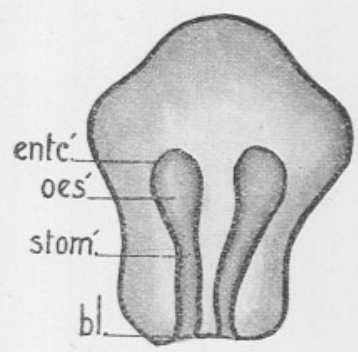

FIG, 1 .

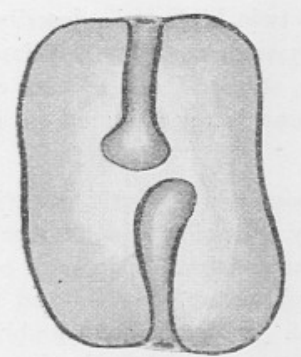

FIG. 4.

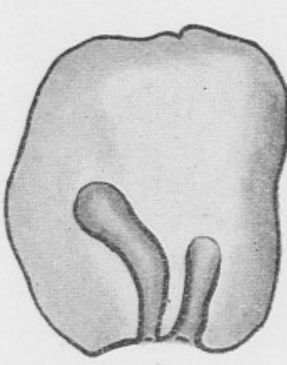

FIG, 2.

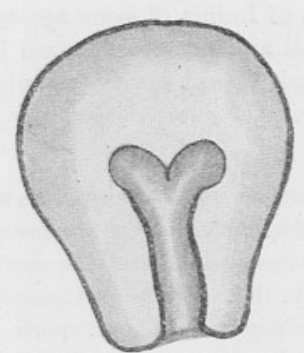

FIG. 5.

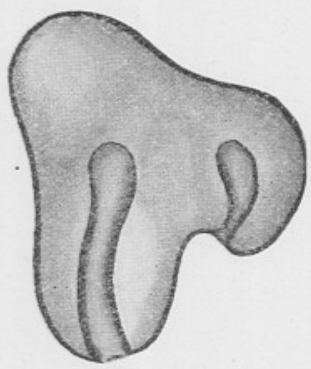

Fig. 3.

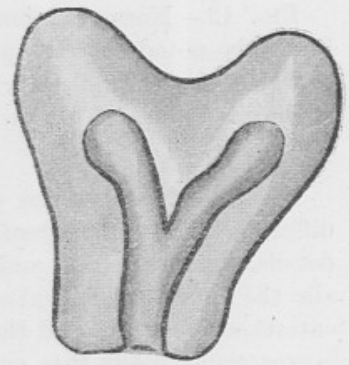

FIG. 6.

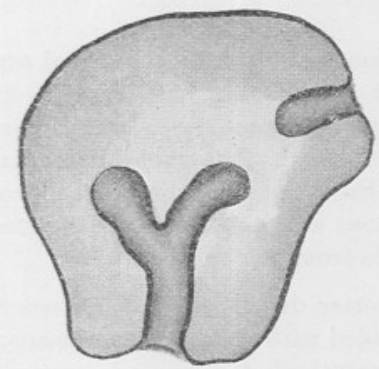

FIG, 7 .

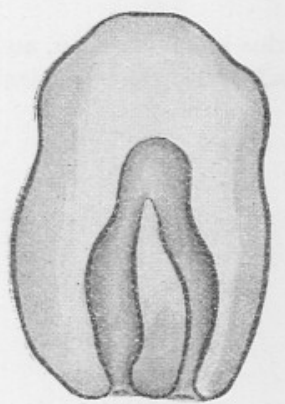

FIG. 9.

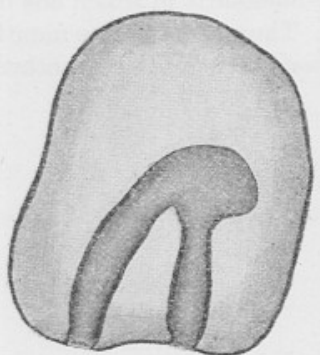

FIg. 10.

[ 585 ]

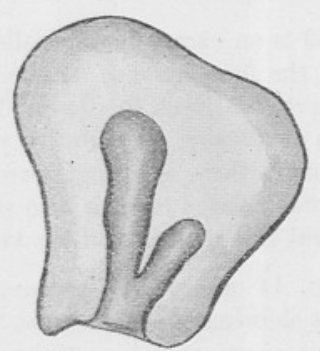

Fig. 8.

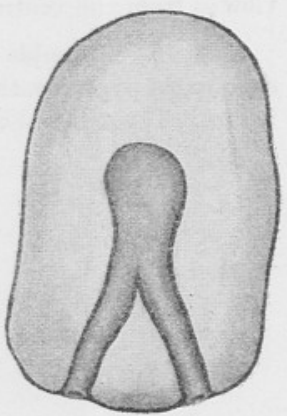

FIs. 11.

NEW SERIES,-VOL, $x$, No. 4. MAY, 1915. 


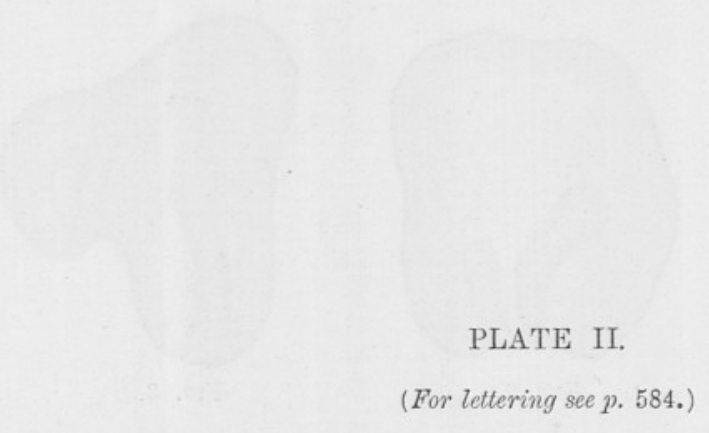

FIG. 12.-Normal bipinnaria of Luidia of same age as the twin bipinnariæ described. It will be noted that the preoral and postoral ciliated bands are completely developed and that in the alimentary canal, buccal cavity, œsophagus, stomach, and rectum can all be made out. There is a pair of enterocoeles, the left one being provided with a hydropore.

Figs. 13-21.-A series of double monster bipinnariæ about six days old, showing different kinds and degrees of duplicity. Here we must pay attention to a number of details, e.g. the preoral and postoral bands and the surface areas which they mark out, also the mouth and buccal cavity, the œsophagus, stomach, and rectum, the right and left enterocoelic cavities and the hydropore and hydroporic canal. In general the doubling is greater internally than externally, the enterocoeles and various parts of the food-canal being sometimes in two sets without a corresponding degree of division being exhibited on the surface of the body.

Fig. 13 is an example of parallel lateral union, as seen from the dorsal aspect. The whole of the food-canal is doubled, the mouth and anus in both cases looking in the same direction. Each food-canal has its own pair of enterocoeles, the left one in both instances developing a hydropore and hydroporic canal. The whole bipinnaria is broader than normal; there is a single preoral ciliated band enclosing the widened frontal field; the postoral ciliated band is also single, but shows a deep backwardly directed sinus on the ventral side marking off the twin anal fields from one another.

In FIG. 14 one set of structures is much better developed than its neighbour, the latter not showing mouth or anus, though provided with osophagus, stomach, intestine, and a pair of enterocoeles. Only one of the preoral ciliated bands is properly differentiated, viz. that in connection with the frontal end of the better developed twin. The view is from the ventral aspect.

FIG. 15.-A double monster bipinnaria in which one of the twins is smaller than, and set at right angles to, the other. The smaller has no mouth and its frontal field is deficient in size. The postoral ciliated bands run into one another. 


\section{PLATE III.}

(For lettering see p. 584.)

FrG. 16.-A bipinnaria in which there is doubling of the mouth, buccal cavity, and first portion of osophagus. The anterior end of the archenteron at the end of gastrulation must have exhibited a very slight degree of doubling. The frontal extremity of the larva is broadened, but in other respects the bipinnaria looks normal ; cf. Fig. 5 .

FIG. 17.-A bipinnaria with anterior doubling and posterior union. The two frontal fields and buccal cavities face one another and lead into a single osophagus which is continued backwards into a single stomach, intestine, and rectum, the anus being in the middle of the posterior surface. There are two pairs of enterocoeles, the left enterocoele of the right twin and the right enterocoele of the left twin being shown in the drawing, and the first-named has a hydroporic opening. The two preoral ciliated bands are distinct from one another, but the postoral bands are continuous on opposite sides. The circumoral food-collecting areas are also united.

FIG. 18.-A double monster bipinnaria showing symmetrical ventral union of the twin components, the fusion being somewhat greater at the anterior than at the posterior end of the composite larva. There are two frontal areas bounded by preoral ciliated bands on opposite sides of the bipinnaria, but each frontal area and ciliated band is to be looked upon as composite, that is, derived in part from one and in part from the other of the twin components. The buccal cavity is single, but also composite, and it communicates with the surface by two mouth openings on opposite sides of the larva. The two postoral ciliated bands are ununited though they approach one another posteriorly. Esophagus, stomach, etc. are separate and there are two pairs of enterocoelic pouches. The circumoral food-collecting areas merge into one another.

FIG. 19.-A bipinnaria showing posterior doubling of the principal internal structures. The view is from the dorsal aspect. The preoral ciliated band, the buccal cavity, and the first part of the osophagus are single, while the rest of the œsophagus, the stomach, and the rectum are doubled. Note as regards the enterocoeles that the left one of the right twin and the right one of the left twin have fused together to form a single composite sac provided with a hydropore. The circumoral fields run freely into one another on the ventral aspect of the larva.

FIG. 20.-A double monster bipinnaria with the components united back-to-back by their dorsal body-walls. Internally there is a composite stomach, but otherwise the food-canals are separate. The rectum and anus of the twin to the left of the drawing were lost. The two preoral and postoral bands and the two circumoral areas have remained separate on either side, and there are two pairs of enterocoelic pouches. As regards internal structure we may describe this specimen as anakatadidymous, that is, showing duplicity both anteriorly and posteriorly.

FIG. 21.-A double monster bipinnaria in which although the buccal cavity and the rectum are single, there is doubling of the intervening regions, namely, the cesophagus and stomach. The view is from the dorsal aspect, and the duplex structures lie side by side, and look in the same direction. Three enterocoelic sacs are present. The middle one possesses a hydropore and has evidently arisen by the fusion of a right sac belonging to a left twin with a left sac belonging to the right twin. Compare with Fig. 19. In other respects the bipinnaria, though slightly broader than usual in its middle region, is superficially almost normal. As far as internal structure is concerned we may describe this bipinnaria as exhibiting the mesodidymous condition. 
